\title{
Analysis of Santa's river water pollution caused by the environmental liability of Ticapampa using grey clustering method
}

\author{
Alexi Delgado ${ }^{1}$, RhandyHuaccha $^{1}$, William Diaz ${ }^{1}$, JossephRivera $^{1}$, Antony Aguedo $^{1}$, Ch. Carbajal $^{2}$ \\ ${ }^{1}$ Mining Engineering Section, Pontificia Universidad Católica del Perú, Lima-Peru, kdelgadov@ pucp.edu.pe \\ ${ }^{2}$ AdministrationProgram, Universidad de Ciencias y Humanidades, Lima-Peru, chcarbajal@uch.edu.pe
}

\begin{abstract}
In Peru, many environmental liabilities produce Acid Mine Drainage (AMD) which flow into rivers affecting their water quality, likewise, many of these liabilities transport large amounts of heavy metals, endangering every water-dependent living organism. In this context, for the evaluation of the parameters involved, we used the grey clustering method, which, based on the theory of grey systems, is presented as a remarkable alternative to the classical statistical methods. In this study we assessed the impact of the Ticapampa environmental liability on the water quality of Santa river using data collected in 2010 from four strategically located monitoring points along the river. The analyzed parameters were evaluated according to the parameters established by DS $\mathrm{N}^{\circ}$ 004-2017-MINAM. Results showed that water quality from monitoring points located upstream (P1) and downstream (P2) with respect to the location of the environmental liability and according to Peruvian law, were of A1 (good) quality; which means that it can be purified using disinfectants. On the other hand, at two points located within the limit of the liability, the water quality was identified as A2 (moderate) and A3 (low) quality, which means it can be purified using conventional and special treatment respectively. Therefore, the grey clustering method has proven to be of great utility for water-quality-assessment related studies and can be applied in other studies which focus on this kind of analysis. In addition, the present results can be useful for Peruvian authorities in their decision making benefiting the communities nearby, animals and environment of study.
\end{abstract}

Key words :Environmental Liability, Grey Clustering, Water Quality.

\section{INTRODUCTION}

The present article highlights the negative impact caused by the presence of the Ticapampa environmental liability (polymetallic tailings pond / Ticapampa district - Recuay province - Ancash region), which has negative impact on the water quality of the middle basin of the Santa River. This problem is the main factor of water pollution in the river, and it affects directly the Ticapampa population quality of life. Nevertheless, this problem can persist for decades and even hundreds of years, because once the productive cycle of the mine is finished, they become one of the main sources of surface and underground water contamination in the world [1]. Therefore, in this article, a water quality assessment is sought, which is why the Grey Clustering Method will be applied.

The Grey Clustering Method is based on the grey system theory which was developed by Deng [2], and CTWF (Center-point Triangular Whitenization weight Functions) and it will be used in order to classify our objectives in defined classes called grey classes [3]. Currently, there are several methods that perform the evaluation of natural resources such as the Adaptive Neuro-Diffuse Inference System (ANFIS)[4], [5],Delphi [6], Shannon Entropy [7], among others; however, the grey clustering method is the most accurate as it can consider uncertainty in its analysis [8], a helpful quality in the field of study of the present study. In addition, the focus of this method is located within the artificial intelligence that is related to the study of problems with little or limited sample information [9]. Which is the reason why the Grey Clustering method has a wide range of applicability such as problem optimization [10], social impact assessment [11], investment risk decision [12] and water quality studies [13]. Furthermore, it is very important to emphasize that traditional methods cannot develop a complex non-linear equation between standard parameters and water quality grades, since there are many factors that modify water quality. Likewise, due to its great potential it has already been applied to different water-quality-related studies as [14]-[17].

Therefore, the current study will focus on characterizing the type of water identified before, during and after its interaction with the Ticapampa environmental liability. The control points for the assessment were located throughout the river, and at points located close to the tailing to analyze the water contamination due to metals contained in the tailing.

The main objective is to compare the results obtained from the monitoring points to the Peruvian environmental quality standards (ECA), approved by the MINEM (Ministry of 
Energy and Mining of Peru), in order to classify the water in categories. It is worth to mention that the comparison was made based on the following metals: $\mathrm{Al}, \mathrm{As}, \mathrm{Be}, \mathrm{B}, \mathrm{Cd}, \mathrm{Cu}$, $\mathrm{Cr}, \mathrm{P}, \mathrm{Fe}, \mathrm{Mn}, \mathrm{Pb}, \mathrm{Se}$ and $\mathrm{Zn}$. In this case, category 1 indicates that monitored water meet the conditions to be used as water supply for human consumption applying simple disinfection, in accordance to current regulations [18]. In the same way, category 2 indicates that monitored water meet the conditions to be used as water supply for human consumption, prior to conventional treatment, which means two or more of the following processes: coagulation, flocculation, decantation, sedimentation, and/or filtration or equivalent processes; including disinfection [18]. Lastly, category 3 indicates that monitored water meet the conditions as water supply for human consumption, prior to conventional treatment that includes advanced physical and chemical processes such as pre-chlorination, micro-filtration, ultrafiltration, Nano-filtration, activated carbon, reverse osmosis or equivalent processes established by the competent sector [18]. The case study was chosen based on the fact that Ancash region is constantly affected by metal contamination which not only threatens the aquatic ecosystem but also life and health of animals and people in the surrounding area [19].

The structure of the present is as follows: Section 2 will explain the literature review of related researches, carried out either using the Grey Clustering Method or taken in the place of study. In Section 3, the methodology used, which was the Grey Clustering method, will be explained in detail. Section 4 will provide inner details about the case study. In section 5 the results and discussions will be presented. Lastly, Section 6 will show the conclusions of this study.

\section{LITERATURE REVIEW}

In [12], an intelligent decision-making method has been put forward to deal with overseas project loans decision-making, which is based on grey clustering analysis method. Grey cluster analysis is an algorithm based on the classification risk index system that groups the risk of degree of damage into the grey cluster risk index system, and performs the foreign project loan decision to accurately measure it, and can also measure the results as a set of sample data from cluster analysis to arrive at the loan plan for the cluster center decision model to complete the project execution plan outside of loans. The effectiveness of the method through the contrast experiment has been validated.

On the same way, reference [13]proposes a grey clustering method based on improved analytic hierarchy process to evaluate the quality of surface water. The water quality samples of three water periods (Abundant, Normal, and Poor water flow periods) in the four sections of Qingshui River in Duyun City (Tea garden, Youhang, Yingpan and Jiadeng) were selected for evaluation, and the conventional grey clustering method and single factor method were used. The evaluation results were compared and analyzed. The evaluation results show that the improved grey clustering method is more scientific and reasonable and can provide a basis for water quality assessment and water environment management of water environment management departments. Likewise, the research done by A. A. Romero, S. L. Flores, and R. Medina [20], presents a study in regards of the impact of heavy metals presented in the Ticapampa tailing, which are solid mining wastes generated as a result of flotation metallurgical treatment operations. Therefore, the present tailing pond constitutes an important environmental liability that since remote times is generating a high negative environmental impact mainly due to the contamination that this liability causes to the waters of the Santa river basin. In this sense, a geochemical analysis of 14 sampling points was carried out, three of which were highlighted (P190, P192, P197). According to the chemical analysis carried out, these points are the most critical because they contain a greater presence and content of heavy metals.

The fourth paper studied the polluting effect of the Ticapampa mining liability[21]. It establishes that this liability is a polymetallic flotation tailing of copper, lead and zinc sulphide minerals, located in the middle basin of the Santa River, which has been negatively impacted since 1900 by mining activities that took place in Collaracra, El Triunfo and Florida. Likewise, as a result of mining and mineral processing activities, there are some environmental liabilities left such as four polymetallic tailings beds and tailings water filtrations, whose drains are discharged directly into the river, causing a negative impact on its water quality, as a matter of fact, there is no evidence of aquatic life inside this part of the river and the consumption of this water is harmful to living beings.

Lastly, in reference[22] the grey clustering method, which is based on grey systems theory, offers an interesting alternative to assess water quality using artificial intelligence criteria. In this paper, we assess water quality from Santa river watershed according to parameters established by MINAM-Peru (DS N ${ }^{\circ}$ 015-2015). Twenty-one monitoring points from Santa river watershed were analyzed. The results showed that $47.6 \%$ of the monitoring points presented good water quality to consumption of the population, which indicated; $33.3 \%$ of the monitoring points presented moderate water quality to consumption of the population; and $19.1 \%$ of the monitoring points presented low water quality to consumption of the population. Therefore, the methodology showed interesting results that could be applied to others studies on water quality or environmental quality in general.

\section{METHODOLOGY}

The grey clustering method comes as an alternative to evaluate contamination and water management [20] since, in addition of using criteria, it establishes intervals or "grey" classes to determine a contamination ranking. For this reason, it was the chosen method to carry out the study of the analysis of Santa's river water quality. Furthermore, this method is based on the theory of grey systems, which was developed in 1985 by Deng [2] in order to classify objects of observation in definable classes, as well as carrying out studies of various small samples that have little information. It is also worth to 
mention that it can be used through Center-Point Triangular WhitenizationFunctions (CTWF).

In this section, the grey clustering method will be explained, specifically the CTWF method, which is the one we will apply to evaluate the water quality from Santa river. This method will determine if studied objects are within the grey classes we previously defined[2].

First, the method assumes there are ' $n$ ' cluster objects, which are the monitoring points; ' $m$ ' cluster indices, which mean thequantity of water parameters; a set of Grey Classes ' $s$ ' and a set of monitoring values $(i=1,2, \ldots m ; j=1,2, \ldots n)$. Steps of the CTWF method are explained in detail below.

Step 1: Standardize Data

First, the non-dimensioned standard values are established for each of the water quality parameters $(j)$, as established in Peruvian law [13]. The aforementioned is relevant since the data to be grouped can be in different units and could not be processed properly. Likewise, the non-dimensioned monitoring data of each water quality parameter are obtained for each water resource $(i)$ to be evaluated.

Step 2: Establish Grey Functions

Second, the three grey classes or categories of water are shown in Figure 1, as established in Peruvian law [13].

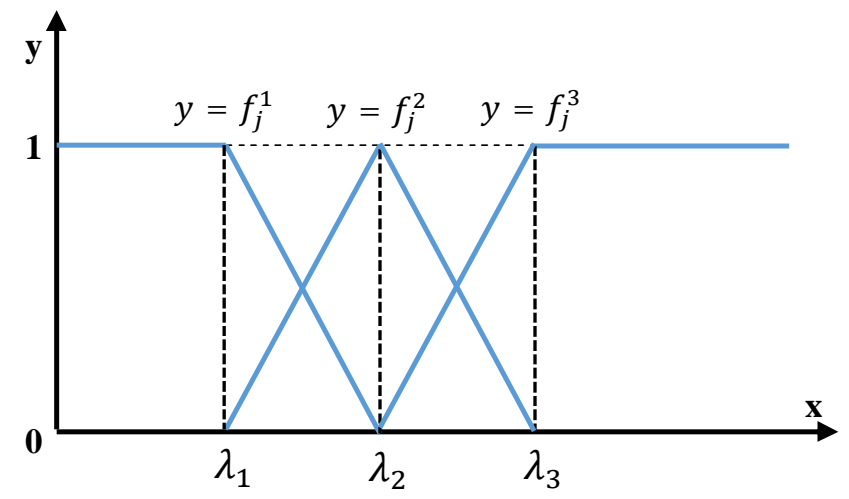

Figure 1: CTWF representation

For the Grey Classes, next functions are defined:

$y=f_{j}^{1}=A_{1}$ : Water might be purified by disinfection.

$y=f_{j}^{2}=A_{2}$ : Water might be purified by conventional treatment.

$$
y=f_{j}^{3}=A_{3} \text { : Water might be purified by special treatment. }
$$

Then, for each class of grey equivalent, $k=1,2,3$ equations are defined based on $j=1,2,3, \ldots n$ for each control point $x_{i j}$ established, in this way the CTWF will be determined by(1) - (3) described below.

$$
f_{j}^{1}\left(x_{i j}\right)=\left\{\begin{array}{c}
0, \in\left[\lambda_{j}^{2},+\infty\right\rangle \\
\frac{\lambda_{j}^{2}-x}{\lambda_{j}^{2}-\lambda_{j}^{1}}, \in\left\langle\lambda_{j}^{1}, \lambda_{j}^{2}\right\rangle \\
1, x \in\left[0, \lambda_{j}^{1}\right]
\end{array}\right.
$$

$$
\begin{gathered}
f_{j}^{2}\left(x_{i j}\right)=\left\{\begin{array}{c}
0, x \in\left[0, \lambda_{j}^{1}\right] U\left[\lambda_{j}^{3},+\infty\right\rangle \\
\frac{\lambda_{j}^{3}-x}{\lambda_{j}^{3}-\lambda_{j}^{2}}, x \in\left\langle\lambda_{j}^{2}, \lambda_{j}^{3}\right\rangle \\
\frac{x-\lambda_{j}^{1}}{\lambda_{j}^{2}-\lambda_{j}^{1}}, x \in\left\langle\lambda_{j}^{1}, \lambda_{j}^{2}\right\rangle
\end{array}\right. \\
f_{j}^{3}\left(x_{i j}\right)=\left\{\begin{array}{c}
0, x \in\left[0, \lambda_{j}^{2}\right] \\
1, x \in\left[\lambda_{j}^{3},+\infty\right\rangle \\
\frac{x-\lambda_{j}^{2}}{\lambda_{j}^{3}-\lambda_{j}^{2}}, x \in\left\langle\lambda_{j}^{2}, \lambda_{j}^{3}\right\rangle
\end{array}\right.
\end{gathered}
$$

Step 3: Clustering Weight

In this section the clustering weight $\left(n_{j}\right)$ of each parameter is calculated, according to subcategories of the Peruvian law by (4).

$$
n_{j}^{k}=\frac{1 / \lambda_{j}^{k}}{\sum_{j=1}^{m} 1 / \lambda_{j}^{k}}
$$

\section{Step 4: Cluster Coefficient}

The determination of the integral clustering coefficient $\sigma_{i}^{k}$ for each established control point $i, i=1,2, \ldots, m$,are calculated by (5), with respect to each defined gray class $k, k=1,2,3$.

$$
\sigma_{i}^{k}=\sum_{j=1}^{n} f_{j}^{k}\left(x_{i j}\right) \cdot n_{j}
$$

Where the value of $f_{j}^{k}\left(x_{i j}\right)$ originates from the CTWF values and $n_{j}$ is the weight of each parameter.

Step 5: Clustering

Finally, the category to which $k *$ belongs will be determined according to the maximum classification coefficients obtained for each of the control points studied as represented in (6).

$$
\max _{1 \leq k \leq s}\left\{\sigma_{i}^{k}\right\}=\left\{\sigma_{i}^{k *}\right\}
$$

\section{CASE STUDY}

The assessment of the water quality from Santa river watershed close to the environmental liability located in Ticapampa was conducted on four monitoring points strategically identified along the river.

\subsection{Context Description}

Ticapampa district is located in the department of Ancash, on the north of Lima, Peru. The environmental liability is located within the limits on the district and next to the river, as shown in Figure 2. A wide view of the district itself located in the region of Ancash can be seen in Figure 3. 


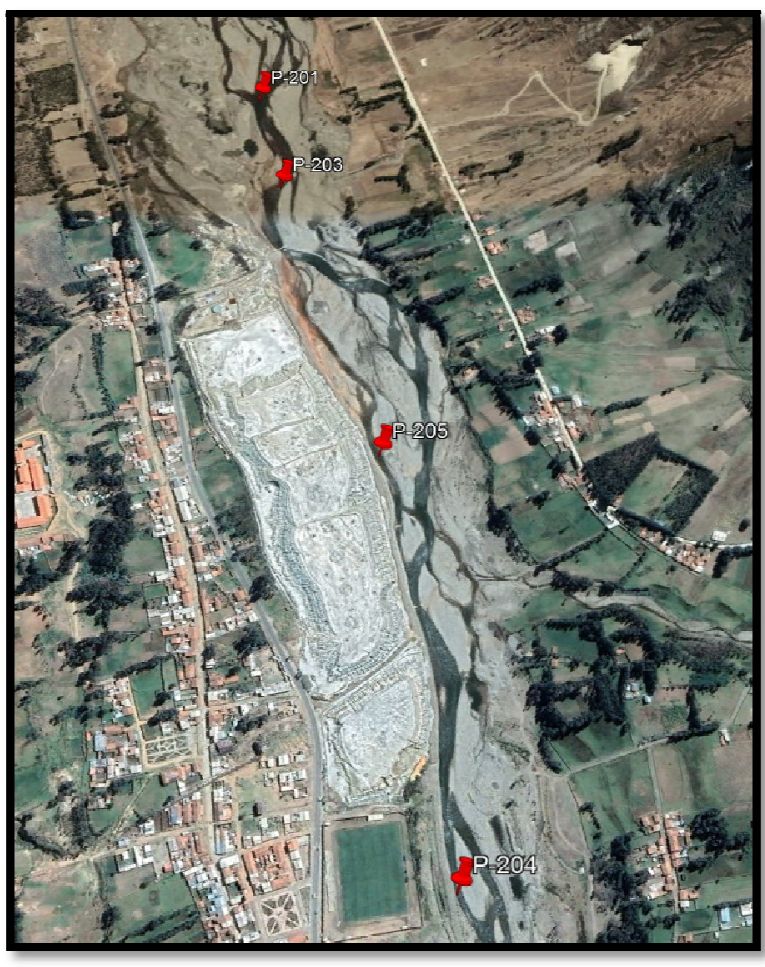

Figure 2: Ticapampa's environmental liability and Santa River

On the other hand, the Santa River is located in the department of Ancash, Peru as well, and ends its path on the Pacific Ocean, as shown in Figure 3 and Figure 4.

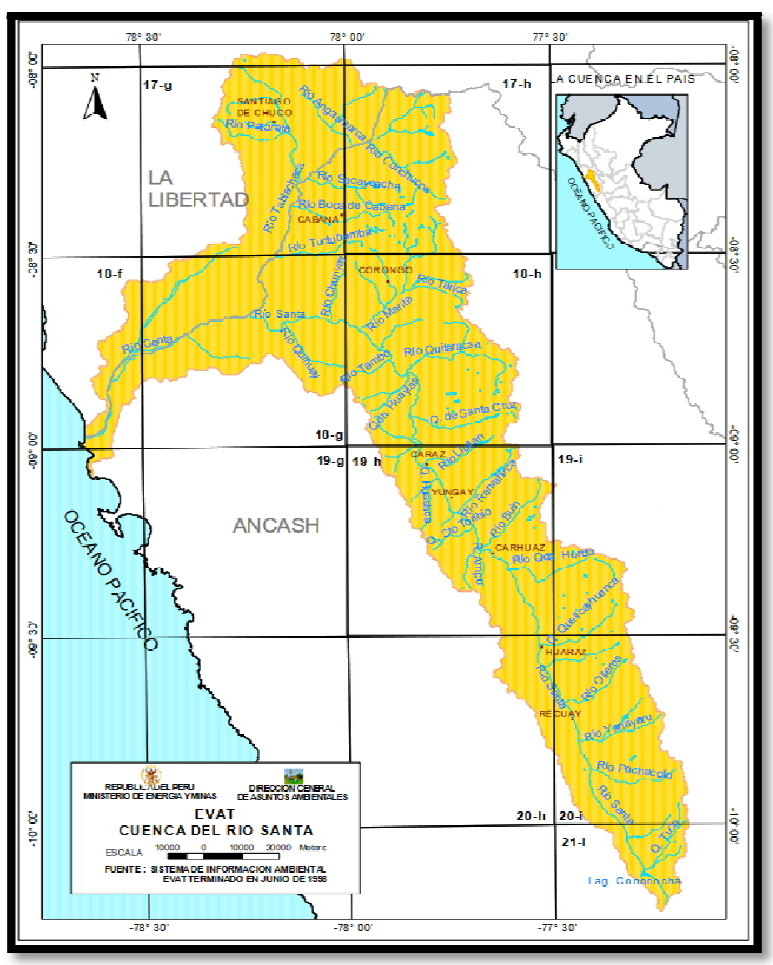

Figure 3: Santa River

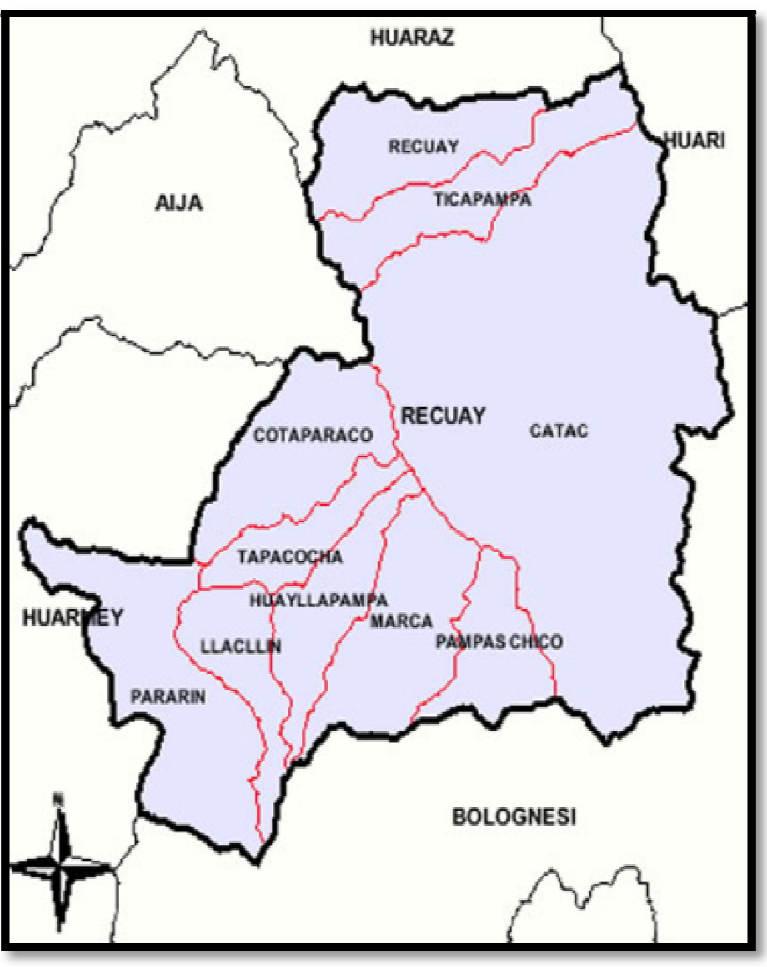

Figure 4: Location of Ticapampa district

The monitoring points according to their relative location are shown in Table 1.

Table 1: Monitoring points of Santa River

\begin{tabular}{|c|c|c|c|c|}
\hline Point & Code & East & North & Altitude \\
\hline 1 & P204 & 232308 & 8920770 & 3446 \\
\hline 2 & P205 & 232229 & 8921060 & 3456 \\
\hline 3 & P203 & 231910 & 8921694 & 3459 \\
\hline 4 & P201 & 231910 & 8921694 & 3454 \\
\hline
\end{tabular}

\subsection{Calculations using CTWF methodology}

The calculations made for the CTWF method will be presented on the following steps as explained in section 3 .

Step 1: Standardize Data

First, the non-dimension values based on the Peruvian law DS $\mathrm{N}^{\circ}$ 004-2017-MINAM for each selected parameter are presented on the following Table 2. It is important to mention that some values shown in the Table below were adjusted using the arithmetic average procedure in order to being able to apply the Grey Clustering method in this analysis.

Table 2: Monitoring points of Santa River

\begin{tabular}{|c|c|c|c|c|}
\hline \multirow{2}{*}{ Parameter } & \multirow{2}{*}{ Code } & \multicolumn{3}{|c|}{ Sub Category } \\
\cline { 3 - 5 } & & $\mathbf{A 1}$ & $\mathbf{A 2}$ & $\mathbf{A 3}$ \\
\hline Aluminum & $\mathrm{C} 1$ & 0.900 & 2.950 & 5.000 \\
\hline Arsenic & $\mathrm{C} 2$ & 0.010 & 0.080 & 0.150 \\
\hline Beryllium & $\mathrm{C} 3$ & 0.012 & 0.040 & 0.100 \\
\hline Boron & $\mathrm{C} 4$ & 1.400 & 2.400 & 3.400 \\
\hline Cadmium & $\mathrm{C} 5$ & 0.003 & 0.005 & 0.010 \\
\hline Copper & C6 & 1.000 & 2.000 & 3.000 \\
\hline
\end{tabular}




\begin{tabular}{|c|c|c|c|c|}
\hline Chrome & C7 & 0.040 & 0.050 & 0.060 \\
\hline Phosphorus & C8 & 0.100 & 0.150 & 0.200 \\
\hline Iron & C9 & 0.300 & 1.000 & 5.000 \\
\hline Manganese & C10 & 0.300 & 0.400 & 0.500 \\
\hline Lead & C11 & 0.010 & 0.030 & 0.050 \\
\hline Selenium & C12 & 0.040 & 0.045 & 0.050 \\
\hline Zinc & C13 & 3 & 4 & 5 \\
\hline
\end{tabular}

values. The calculations of the four monitoring points for the first seven parameters were obtained as shown in Table 4.

Table 4: CTWF value of each four monitoring points

\begin{tabular}{|c|c|c|c|c|c|c|c|}
\hline P1 & $\mathbf{C 1}$ & $\mathbf{C 2}$ & $\mathbf{C 3}$ & $\mathbf{C 4}$ & $\mathbf{C 5}$ & $\mathbf{C 6}$ & $\mathbf{C 7}$ \\
\hline$f_{1}$ & 1 & 1 & 0.964 & 1 & 0 & 1 & 0 \\
\hline$f_{2}$ & 0 & 0 & 0.036 & 0 & 0 & 0 & 0 \\
\hline$f_{3}$ & 0 & 0 & 0 & 0 & 1 & 0 & 1 \\
\hline $\mathbf{P 2}$ & $\mathbf{C 1}$ & $\mathbf{C 2}$ & $\mathbf{C 3}$ & $\mathbf{C 4}$ & $\mathbf{C 5}$ & $\mathbf{C 6}$ & $\mathbf{C 7}$ \\
\hline$f_{1}$ & 1 & 0.571 & 1 & 1 & 0 & 1 & 0 \\
\hline$f_{2}$ & 0 & 0.429 & 0 & 0 & 0 & 0 & 0 \\
\hline$f_{3}$ & 0 & 0 & 0 & 0 & 1 & 0 & 1 \\
\hline $\mathbf{P 3}$ & $\mathbf{C 1}$ & $\mathbf{C 2}$ & $\mathbf{C 3}$ & $\mathbf{C 4}$ & $\mathbf{C 5}$ & $\mathbf{C 6}$ & $\mathbf{C 7}$ \\
\hline$f_{1}$ & 1 & 0 & 0 & 1 & 0 & 1 & 0 \\
\hline$f_{2}$ & 0 & 0.600 & 0.533 & 0 & 0 & 0 & 0 \\
\hline$f_{3}$ & 0 & 0.400 & 0.467 & 0 & 1 & 0 & 1 \\
\hline $\mathbf{P 4}$ & $\mathbf{C 1}$ & $\mathbf{C 2}$ & $\mathbf{C 3}$ & $\mathbf{C 4}$ & $\mathbf{C 5}$ & $\mathbf{C 6}$ & $\mathbf{C 7}$ \\
\hline$f_{1}$ & 1 & 0.843 & 0.786 & 1 & 0 & 1 & 0 \\
\hline$f_{2}$ & 0 & 0.157 & 1.367 & 0 & 0 & 0 & 0 \\
\hline$f_{3}$ & 0 & 0 & 0 & 0 & 1 & 0 & 1 \\
\hline
\end{tabular}

Step 3: Clustering Weight

The clustering weight of each parameter, in each sub category A shown in Table 2, were calculated using (4). Result values are shown in Table 5.

Table 5: Clustering weight of each parameter

\begin{tabular}{|c|c|c|c|c|}
\hline \multirow{2}{*}{ Parameter } & \multirow{2}{*}{ Weight } & \multicolumn{3}{|c|}{ Sub Category } \\
\cline { 3 - 5 } & & $\boldsymbol{A}_{\mathbf{1}}$ & $\boldsymbol{A}_{\mathbf{2}}$ & $\boldsymbol{A}_{\mathbf{3}}$ \\
\hline Aluminum & $\mathrm{C} 1$ & 0.087 & 0.069 & 0.068 \\
\hline Arsenic & $\mathrm{C} 2$ & 0.212 & 0.069 & 0.061 \\
\hline Beryllium & $\mathrm{C} 3$ & 0.112 & 0.087 & 0.058 \\
\hline Boron & $\mathrm{C} 4$ & 0.045 & 0.069 & 0.081 \\
\hline Cadmium & $\mathrm{C} 5$ & 0.053 & 0.082 & 0.069 \\
\hline Copper & $\mathrm{C} 6$ & 0.053 & 0.069 & 0.077 \\
\hline Chrome & $\mathrm{C} 7$ & 0.033 & 0.069 & 0.096 \\
\hline Phosphorus & $\mathrm{C} 8$ & 0.040 & 0.069 & 0.086 \\
\hline Iron & $\mathrm{C} 9$ & 0.185 & 0.144 & 0.048 \\
\hline Manganese & $\mathrm{C} 10$ & 0.035 & 0.069 & 0.092 \\
\hline Lead & $\mathrm{C} 11$ & 0.079 & 0.069 & 0.069 \\
\hline Selenium & $\mathrm{C} 12$ & 0.030 & 0.069 & 0.103 \\
\hline Zinc & $\mathrm{C} 13$ & 0.035 & 0.069 & 0.092 \\
\hline
\end{tabular}

Step 4: Cluster Coefficient

Then, the cluster coefficient values had to be calculated by means of (5). Such results are shown in Table 6.

Table 6: Maximum value of the cluster coefficient of each monitoring point

$$
f_{1}^{3}\left(x_{i j}\right)=\left\{\begin{array}{c}
\frac{x-0.789}{1.974-0.789}, x \in\langle 0.789,1.974\rangle \\
1, x \in[1.974,+\infty\rangle \\
0, x \in[0,0.789]
\end{array}\right.
$$

After the values shown in Table 3 were analyzed using the criteria followed by the $(6)-(8)$ to calculate the CTWF

Clustering Coefficient

\begin{tabular}{|c|c|c|c|}
\hline \multicolumn{4}{|c|}{ Clustering Coefficient } \\
\hline Points & $\boldsymbol{A}_{\mathbf{1}}$ & $\boldsymbol{A}_{\mathbf{2}}$ & $\boldsymbol{A}_{\mathbf{3}}$ \\
\hline P1 & 0.761 & 0.003 & 0.423 \\
\hline P2 & 0.674 & 0.029 & 0.423 \\
\hline P3 & 0.441 & 0.088 & 0.475 \\
\hline P4 & 0.522 & 0.700 & 0.448 \\
\hline
\end{tabular}


Step 5: Clustering

After having calculated the values shown in Table 6, we apply a condition that chose the maximum value within the three sub categories for each monitoring point. It is decided that the chosen value belongs to a determined grey class. For each monitoring point, the results are shown in Table 7.

Table 7: Maximum value of the cluster coefficient of each parameter with its category

\begin{tabular}{|c|c|c|}
\hline \multicolumn{3}{|c|}{ Results } \\
\hline Points & Max- Coef & Category \\
\hline P1 & 0.761 & A1 \\
\hline P2 & 0.674 & A1 \\
\hline P3 & 0.475 & A3 \\
\hline P4 & 0.700 & A2 \\
\hline
\end{tabular}

\section{RESULTS AND DISCUSSION}

\subsection{Case Study}

As shown in Table 7, monitoring points P1 and P2, which represent upstream and downstream taken data respectively; evidence, according to Peruvian law, a good water quality. This results mean the quality of water could be even better if purified using disinfectants. On the other hand, P4 presented moderated water quality, which can also be purified by using conventional treatments. Meanwhile, in P3 the quality of water was qualified as low, requiring a special treatment in order to purify the water [18], [23].

An explanation to the fact that water quality identified in P1 and $\mathrm{P} 2$ are somehow similar could be that high concentrated contaminating elements located along the hillside of the tailing had been sedimenting over time. Because of this, water quality in P3 and P4 is qualified as low and needs treatments to make it able for human consumption. It is worth to mention that some elements have not been sedimented but transported which can justify the presence of high concentrated elements like arsenic downstream [24]. The lack of a geomembrane, which prevents acid drainage from the tailing to the subsoil, also contributes to the contamination of the river, as results showed the presence of heavy metals such as cadmium in the water.

\subsection{Methodology}

Compared to many classic multiple-analysis criteria, which tend not to consider incertitude in their analysis; the Grey Clustering Method may be the most appropriate method to use in this type of project, as its degrees of importance develop accuracy and decrease uncertainty [22], [25], [26].

\section{CONCLUSIONS}

Results showed that the water quality of Santa River within limits of Ticapampatailing are classified as A2 and A3 which means there is a presence of heavy metals; however, upstream and downstream results were A1. This means that Santa River has a purifier power due to its own turbulent flow conditions but Ticapampa tailing ends up polluting it. Also, that results could help the local government to take action and propose measures that prevent the Santa River to keep being contaminated in behalf of the communities and animals nearby.

Grey clustering method has the advantage to classify objects within grey classes systems which could end up being more adequate than classical approaches of multi-criteria analysis that do not consider uncertainty within their analysis and the importance degree of criteria.

Peru has around 8000 mining environmental liabilities, many of them are usually located nearby local rivers, like Ticapampa liability. This fact is contributing to the deterioration of the image most mining enterprises are trying to pull out, which is 'Environmentally Responsible Mining'. On this behalf, the grey clustering method surges as a possible tool to assess the impact of these liabilities on the environment.

\section{REFERENCES}

1. O. Aduvire, Drenaje Ácido de Mina. Generación y Tratamiento, Inst. Geológico y Min. España, 1991.

2. J. Deng, Generation Functions of Grey Systems. Fuzzy Mathematics, 5th ed. .

3. A. Delgado, H. Reyes, I. Romero, and C. C. Mancilla, Social impact assessment using the grey clustering method: A case study on a mining project, 2019, pp. $1-5$.

4. Z. Fu, J. Cheng, M. Yang, and J. Batista, Prediction of industrial wastewater quality parameters based on wavelet de-noised ANFIS model, in 2018 IEEE 8th Annual Computing and Communication Workshop and Conference, CCWC 2018, 2018, vol. 2018-January, pp. 301-306.

5. E. Sutoyo, R. R. Saedudin, I. T. R. Yanto, and A. Apriani, Application of adaptive neuro-fuzzy inference system and chicken swarm optimization for classifying river water quality, in Proceeding - 2017 5th International Conference on Electrical, Electronics and Information Engineering: Smart Innovations for Bridging Future Technologies, ICEEIE 2017, 2018, vol. 2018-January, pp. 118-122.

6. P. Das Saha, Water quality characteristics of different industrial wastewater by Delphi water quality index method, Int. J. Environ. Eng., vol. 6, no. 1, p. 1, 2014.

7. A. Delgado and I. Romero, Environmental conflict analysis on a hydrocarbon exploration project using the Shannon entropy, in Proceedings of the 2017 Electronic Congress, E-CON UNI 2017, 2017, vol. 2018-January, pp. 1-4.

8. A. Delgado, B. Ortiz, R. Hurtado, R. Monge, A. Perez, and C. Carbajal, Applying grey systems to assess social impact on the extraction phase of the Palma mining project in Peru, Int. J. Adv. Trends Comput. Sci. Eng., vol. 9, no. 4, pp. 4295-4301, 2020.

9. S. Liu and Y. Lin, Grey Systems: Theory and Applications. Berlín: Springer, 2010. 
10. C. Bindu, M. Padmaja, and J. A. Chandulal, Evaluating Web Sites Based on GHAP, Int. J. Comput. Sci. Eng., vol. 2, no. 3, pp. 674-679, 2010.

11. H. Li, Y. Fu, W. Tang, and W. Yang, The application of grey clustering analysis on social impact assessment of natural forest protection project, in Proceedings 2010 IEEE International Conference on Information Theory and Information Security, ICITIS 2010, 2010, pp. 776-780.

12. L. Ke, S. Xiaoliu, T. Zhongfu, and G. Wenyan, Grey Clustering Analysis Method for Overseas Energy Project Investment Risk Decision, Syst. Eng. Procedia, vol. 3, pp. 55-62, 2012.

13. J. Wang et al., Application of Grey Clustering Method Based on Improved Analytic Hierarchy Process in Water Quality Evaluation, MATEC Web Conf., vol. 246, pp. 3-7, 2018.

14. L. Wang, K. Lai, and W. Zhou, Application of grey clustering method for water quality evaluation in Fenchuan river Yan'an Baota area, in ISWREP 2011 Proceedings of 2011 International Symposium on Water Resource and Environmental Protection, 2011, vol. 2, pp. 838-841.

15. J. Chen, S. Zhao, and Y. Weng, Research on river water quality assessment of eastern route of south-to-north water transfers based on grey cluster evaluation model, in 2009 IEEE International Conference on Grey Systems and Intelligent Services, GSIS 2009, 2009, pp. 882-887.

16. C. Zhu and Q. Liu, Evaluation of water quality using grey clustering, in Proceedings - 2009 2nd International Workshop on Knowledge Discovery and Data Mining, WKKD 2009, 2009, pp. 803-805.

17. A. Delgado, J. Soto, and F. Valverde, Evaluation of the drinking water consumption in Lima city using the grey clustering method, in 17 th LACCEI International Multi-Conference for Engineering, Education, and Technology, 2019.

18. MINAM, Ministerio del Ambiente (MINAM). Estándares de Calidad Ambiental para Agua (ECA), El Peru., pp. 6-9, 2017.

19. R. Dallinger and H. Kautzky, The importance of contaminated food for the uptake of heavy metals by rainbow trout (Salmo gairdneri): a field study, Oecologia, vol. 67, no. 1, pp. 82-89, Aug. 1985.

20. A. Romero, R. Medina, and S. Flores, Estudio de los metales pesados en el relave abandonado de Ticapampa, Rev. del Inst. Investig. la Fac. Ing. Geológica, Minera, Met. y Geográfica, vol. 11, no. 22, pp. 13-16, Jan. 2012.

21. A. Romero, S. Flores, and W. Pacheco, Estudio de la calidad de agua de la cuenca del río Santa, Rev. del Inst. Investig. FIGMMG, vol. 13, no. 25, pp. 61-69, 2010 .

22. A. Delgado, D. Vriclizar, and E. Medina, Artificial intelligence model based on grey systems to assess water quality from Santa river watershed, in Proceedings of the 2017 Electronic Congress, E-CON UNI 2017, 2017, vol. 2018-January, pp. 1-4.
23. A. Delgado and I. Romero, Environmental conflict analysis using an integrated grey clustering and entropy-weight method: A case study of a mining project in Peru, Environ. Model. Softw., vol. 77, pp. 108-121, Mar. 2016.

24. L. N. Zhang, F. P. Wu, and P. Jia, Grey Evaluation Model Based on Reformative Triangular Whitenization Weight Function and Its Application in Water Rights Allocation System, Open Cybern. Syst. J., vol. 7, no. 1, pp. 1-10, Jul. 2013.

25. A. Baykasołlu and I. Gölcük, Development of a novel multiple-attribute decision making model via fuzzy cognitive maps and hierarchical fuzzy TOPSIS, Inf. Sci. (Ny)., vol. 301, pp. 75-98, Apr. 2015.

26. R. Campos-Climent, V.; Apetrei, A.; Chaves-Ávila, Delphi method applied to horticultural cooperatives, Manag. Decis., vol. 50, pp. 1266-1284, 2012. 